\title{
La banca privada en el crecimiento económico de un país
}

\section{Private banking in the economic growth of a country}

Mario Enrique Vásquez Jiménez

Universidad Internacional del Ecuador, Ecuador

Autor para correspondencia: mavasquezj@gmail.com

Fecha de recepción: 28 de febrero de 2016 - Fecha de aceptación: 14 de abril de 2016

\section{Resumen}

Si todos los países que tienen un sistema financiero desarrollado, fuerte, y sin problemas contribuyeran al desarrollo sostenido de la economía de un país, entonces, la solución al subdesarrollo económico de los países podría estar enfocada a que los gobiernos le presten la ayuda necesaria a la banca privada. Este estudio presentara como la banca privada puede ayudar al crecimiento económico de un país.

Palabras claves: crecimiento económico; banca; desarrollo

\begin{abstract}
If all countries with a developed, strong and smooth financial system contribute to the sustained development of the economy of a country, then the solution to the economic underdevelopment of the countries could be focused on governments to provide them the necessary assistance private banking. This study presented as private banks can help the economic growth of a country.
\end{abstract}

Key words: economic growth; banking; development 


\section{Introducción}

El desarrollo de los países puede estar sustentado en el crecimiento de ciertos sectores (Agrícola, manufacturero, minero, petrolero, financiero, entre otros), se cree que uno de los puntos más sensibles para la sostenibilidad económica es el sistema financiero.

Podemos tomar como un punto de referencia la crisis financiera que sufrió Estados Unidos 2007 por la ruptura de la burbuja inmobiliaria, este problema se nace a raíz del estallido de la burbuja del internet en el año 2001, en donde los entes de regulación bajaron las tasas alrededor del 1\% como medida para poder recuperar la economía mediante el sistema financiero, llevando esto a la adquisición de dinero barato y puede ser que a una sobreinversión el sector inmobiliario, para controlar este sobrendeudamiento en el lapso del 2004 y 2006 optaron por elevar las tasas de interés a niveles superiores al 5\%, con esta acción comenzaron a observar los primeros estragos de la crisis anunciada, aumento de la tasa de mora y una desaceleración en ejecución de préstamos, en el 2007 los mercados comenzaron a darse cuenta que los bancos no tenían los activos suficiente para respaldar su deuda, determinando problemas en la bolsa de valores y en los fondos de inversión, esto se agudizo cuando algunos bancos y fondos de inversión comenzaron a anunciar su quiebra generando un alto grado de incertidumbre y volatilidad en todos los participantes de los mercados financieros, llevando a los inversionistas a no querer asumir riesgo y a realizar inversiones con altos grado de seguridad, como son las letras del tesoro y bonos del gobierno Norteamericano, notándose claramente una retracción de capitales para el resto del mundo, entrando en una recesión económica Estados Unidos y otros países que orientaban su inversión a este.

La crisis financiera estadounidense dio inicio a otro problema financiero mundial, en especial en Europa y Japón, por varios factores, aumento de precios en los commodities, el aumento de la tasa de interés, aumento de la inflación. Siendo Estados Unidos uno de los mayores receptores de inversión su crisis origino otras, ocasionando una crisis financiera internacional y recesión económica mundial.

En el 2008 los gobiernos de países europeos no estimaron que la crisis iba a alcanzar a estos países y no tomaron coberturas para minimizar el efecto, por esta razón países como Alemania y Francia tuvieron un de crecimiento en su economía, para el siguiente año España e Italia fueron los países más afectados con la crisis. En España estallando también la burbuja inmobiliaria por las altas tasas de interés que se generaron y elevados dividendos en los pagos de los préstamos, haciendo que la mora de los créditos aumente y mermando la posibilidad de generar nuevos créditos para inyectar capital fresco a la economía, ahora podemos observar los altos niveles de desempleo que está viviendo este país que puede ser causa de la crisis financiera de este, entonces, debemos preguntarnos, ¿Los países que tiene un sistema financiero privado desarrollado y sin problemas, tienen un crecimiento sostenido en su economía?.

Si todos los países que tienen un sistema financiero desarrollado, fuerte, y sin problemas contribuyeran al desarrollo sostenido de la economía de un país, entonces, la solución al subdesarrollo económico de los países podría estar enfocada a que los gobiernos le presten la ayuda necesaria a la banca privada. En la actualidad, los países de Latinoamérica en su gran mayoría son de tendencia socialista y están tomando medidas que posiblemente estén limitando 
el desarrollo de la banca privada, en algunos casos, la nacionalización de ciertos bancos y en otros la asignación e nuevos impuestos a los ingresos, esto podría llevar a un aumento del costo del financiamiento y con esto una menor asignación de recursos por medio de estas instituciones, ¿Puede esto ser causa del limitante crecimiento de los países Latinoamericano?.

En este artículo está orientado a estudiar la incidencia que tiene la banca privada en desarrollo económico de un país, para esto no hemos planteado la siguiente hipótesis:

\section{H1. Hipótesis:}

A una mayor inyección de crédito por medio de la banca privada, existe un mayor crecimiento económico.

\section{Base De Datos}

La base de datos que se utilizó para llevar a cabo la refutación de la hipótesis, es la del Fondo Monetario Internacional, está disponible en internet en la siguiente dirección: www.imf.org.

Se ha tomado como muestra 27 países de todos los continentes, que contaban con la información necesaria para elaborar este estudio.

\begin{tabular}{|c|c|c|c|c|c|c|}
\hline $\begin{array}{l}\text { Country } \\
\text { Group }\end{array}$ & and & $\begin{array}{l}\text { Variación del PIB } \\
\text { Percápita }\end{array}$ & $\begin{array}{ll}\text { Variación } & \text { del } \\
\text { crédito } & \end{array}$ & $\begin{array}{l}\text { Country and } \\
\text { Group }\end{array}$ & $\begin{array}{l}\text { Variación del } \\
\text { PIB }\end{array}$ & $\begin{array}{l}\text { Variación } \\
\text { crédito }\end{array}$ \\
\hline Argentina & & 0.20 & 0.37 & $\begin{array}{l}\text { Korea, } \\
\text { Republic of }\end{array}$ & 0.09 & 0.05 \\
\hline Australia & & 0.18 & 0.07 & Luxembourg & 0.10 & 0.02 \\
\hline Austria & & 0.10 & 0.03 & Mexico & 0.10 & 0.09 \\
\hline Belgium & & 0.08 & 0.04 & Netherlands & 0.07 & 0.02 \\
\hline Brazil & & 0.15 & 0.15 & $\begin{array}{l}\text { Russian } \\
\text { Federation }\end{array}$ & 0.25 & 0.27 \\
\hline $\begin{array}{l}\text { China, } \\
\text { Mainland }\end{array}$ & P.R.: & 0.22 & 0.17 & Singapore & 0.12 & 0.18 \\
\hline $\begin{array}{l}\text { China, } \\
\text { Hong Kong }\end{array}$ & P.R.: & 0.08 & 0.15 & South Africa & 0.04 & 0.03 \\
\hline France & & 0.07 & 0.04 & Spain & 0.06 & 0.00 \\
\hline Germany & & 0.09 & 0.01 & Sweden & 0.16 & 0.05 \\
\hline India & & 0.11 & 0.19 & Switzerland & 0.19 & 0.03 \\
\hline Indonesia & & 0.18 & 0.22 & Turkey & 0.03 & 0.18 \\
\hline Ireland & & 0.04 & 0.03 & $\begin{array}{l}\text { United } \\
\text { Kingdom }\end{array}$ & 0.07 & 0.01 \\
\hline Italy & & 0.06 & 0.03 & United States & 0.03 & 0.06 \\
\hline Japan & & 0.07 & 0.01 & & & \\
\hline
\end{tabular}

Cuadro no.1

\section{Estimación empírica}


Para tratar de refutar con evidencia empírica esta hipótesis, vamos a tomar como factor de medición del crecimiento económico de un país la variación del PIB Per cápita, y para el aporte de capital de la banca privada se va a tomar la variación dela inyección del crédito de bancos privados.

La función a estudiar es:

$Y=F(X)$

Donde:

Y= Variación del PIB Percápita

$\mathrm{X}=$ Variación del crédito de los Bancos Privados

Para este análisis se va a realizar un estudio transversal, midiendo el crecimiento de las variables antes descritas en los años 2010 - 2011 de 27 países.

\section{Falsación de la hipótesis}

La confrontación de la hipótesis nos determina que si tienen correlación positiva la variable variación del PIB Per cápita y variación del crédito de los bancos privados tal cual se muestra en la siguiente tabla:

\begin{tabular}{|c|c|c|c|c|c|c|}
\hline \multicolumn{5}{|c|}{ Resumen del modelo } & & \\
\hline \multirow{2}{*}{\begin{tabular}{|l} 
Modelo \\
1
\end{tabular}} & $\mathrm{R}$ & \multirow{2}{*}{$\frac{R \text { cuadrado }}{375}$} & $\begin{array}{l}\text { R cuadrado } \\
\text { corregida }\end{array}$ & $\begin{array}{l}\text { Error típ. de la } \\
\text { estimación }\end{array}$ & & \\
\hline & .612 & & .350 & .048841448183 & & \\
\hline \multicolumn{7}{|c|}{ ANOVAb } \\
\hline \multicolumn{2}{|l|}{ Modelo } & $\begin{array}{c}\text { Suma de } \\
\text { cuadrados }\end{array}$ & $\mathrm{gl}$ & Media cuadrática & $\mathrm{F}$ & Sig. \\
\hline \multirow[t]{3}{*}{1} & Regresión & .036 & 1 & .036 & 14.996 & .001 \\
\hline & Residual & .060 & 25 & .002 & & \\
\hline & Total & .095 & 26 & & & \\
\hline & & & & & & \\
\hline
\end{tabular}

\begin{tabular}{|c|c|c|c|c|c|c|}
\hline \multicolumn{7}{|c|}{ Coeficientesa } \\
\hline \multirow{2}{*}{\multicolumn{2}{|c|}{ Modelo }} & \multicolumn{2}{|c|}{$\begin{array}{l}\text { Coeficientes no } \\
\text { estandarizados }\end{array}$} & \multirow{2}{*}{$\begin{array}{c}\text { Coeficientes } \\
\text { tipificados } \\
\text { Beta }\end{array}$} & \multirow{3}{*}{$\frac{t}{6.054}$} & \multirow{3}{*}{$\frac{\text { Sig. }}{.000}$} \\
\hline & & B & Error tip. & & & \\
\hline \multirow[t]{2}{*}{1} & (Constante) & .076 & .013 & & & \\
\hline & $\begin{array}{l}\text { Crecimiento } \\
\text { del credito }\end{array}$ & .375 & .097 & .612 & 3.872 & .001 \\
\hline
\end{tabular}

Cuadro no. 2

Como se puede observar en el cuadro numero 1 la asociación que tienen las variables es positiva y del 0.612 , y además en la prueba de significancia y en el F critico el error es menor al 
$5 \%$ y se establece que la variable es estadísticamente significativa y con esto corroboramos que efectivamente existe correlación, y se determina mediante la prueba empírica que $\mathrm{H} \approx \mathrm{b}$.

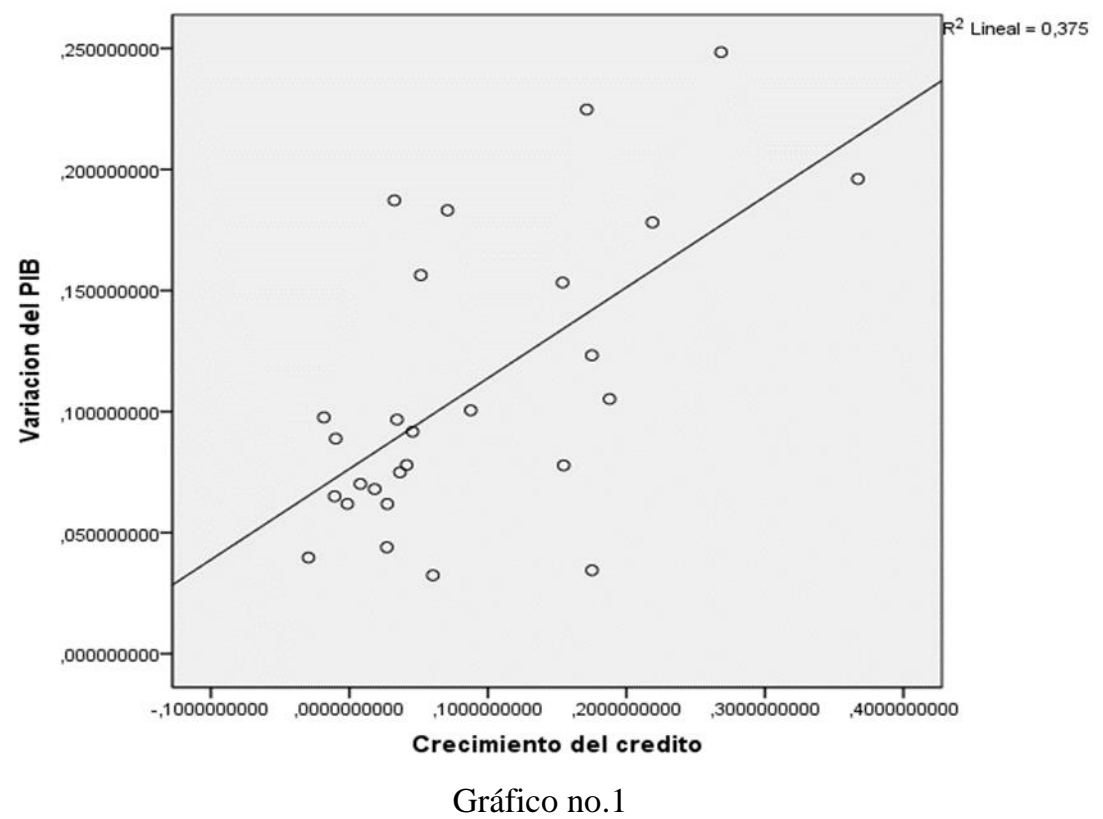

Conclusión

La hipótesis determina que existe una relación positiva entre la variable variación del PIB Per cápita y Variación del Crédito privado, mediante la prueba empírica se pudo comprobar que esto es así, por lo tanto, la hipótesis es aceptada, la cual puede determinar que a un aumento del crédito por parte de los bancos privados puede existir un crecimiento en la economía y que a una disminución del crédito por parte de los bancos privados podría existir un decrecimiento económico.

\section{Propuesta de teoría}

En el estudio realizado, se buscaba determinar si existía algún tipo de relación entre el crecimiento y el desarrollo de la banca privada con el crecimiento económico de un país, y dio como resultado que si tienen una asociación positiva. Se debe realizar un estudio utilizando más variables para determinar con mayor exactitud la incidencia de la banca, tanto en los países considerados como desarrollados y en los del tercer mundo.

Con esto podemos dar paso a paso al análisis de una teoría:

\section{Teoría:}


$\alpha$ : Los propietarios de los bancos privados están en busca de maximizar sus beneficios.

\section{Supuestos:}

- Supuesto auxiliar 1.- $\mathrm{A}^{\prime}:$ Los bancos realizan préstamos a sectores productivos que contribuyen con el crecimiento económico de un país.

- Supuesto auxiliar 2.- A": La inyección de capital por medio de la banca privada coadyuva al crecimiento del beneficio social.

\section{Hipótesis $\beta$ (Modelo)}

$\beta$ : El crecimiento del crédito de las instituciones financieras privadas causa un crecimiento económico de un país.

\section{Bibliografía}

Figueroa, A. (2012) The Alpha - Beta Method Scientific Rules for Economics and the Social Sciences. $1^{\circ}$ edition Cengage Learning: Argentina.

Shiller, R. (2012) Las Finanzas en una Sociedad Justa. Deusto S.A. Edicones: España 